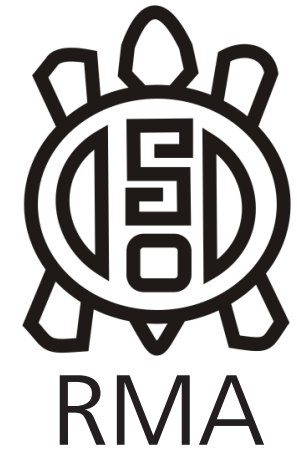

Dossier

\title{
Patrimonios liberadores: El museo como herramienta para la solución de conflictos
}

\author{
Liberating heritage: The museum as a tool for conflict resolution
}

Fabio Alberto López Suárez

Coordinador del Programa de formación en Patrimonio Cultural de Bogotá Civinautas, del Instituto Distrital de Patrimonio Cultural de la Alcaldía de Bogotá-Colombia.

E-mail: fabio.lopez@idpc.gov.co / fabiolopezs@gmail.com

\begin{abstract}
Resumen
La importancia de los Museos como agentes de transformación social llevan a pensar el papel que juegan como instrumento para la resolución de conflictos y de cómo los patrimonios que allí subyacen sean materiales o inmateriales, resultan ser patrimonios liberadores, en la medida que se involucra al sujeto como agente crítico y al ambiente de lo educativo como eje de esa transformación. Recuperar la sensación de libertad, que parece ser una necesidad latente, "aunque en principio nacemos libres", hace parte de la responsabilidad de pertenecer a ese complejo campo de lo cultural, en donde se construyen las nociones de realidad en un entorno tan globalizado y manipulado por los estereotipos y las versiones absolutas que dejan muy poco a la imaginación. A partir del concepto FAKE, recorremos las alternativas para despertar el pensamiento crítico y disponer las herramientas necesarias para generar ambientes de cambio y transformación social.
\end{abstract}

Palabras clave: Patrimonio; Liberta; FAKE; museo; sociedad.

\begin{abstract}
The importance of museums as agents of social transformation lead to think about the role they play as an instrument for the resolution of conflicts and how the underlying assets, whether material or immaterial, turn out to be liberating assets and that individuals are involved as a critical agent and the environment of education as the axis of that transformation. Recover the feeling of freedom, which seems to be a permanent need, "although we are born free in the beginning", is part of the responsibility of belonging to this complex field of culture, where the notions of reality are built in such a globalized environment and manipulated by stereotypes and absolute versions that allow little to the imagination. Based on the FAKE concept, we explore alternatives to awaken critical thinking and provide the necessary tools to generate environments of change and social transformation.
\end{abstract}

Keywords: Heritage; Freedom; FAKE; museum; society.

“Los primeros españoles que vinieron al Nuevo Mundo, vivían aturdidos por el canto de los pájaros, se mareaban con la pureza de los olores y agotaron en poco tiempo una especie exquisita de perros mudos que los indígenas criaban para comer. Muchos de ellos, y otros que llegarían después, eran criminales rasos en libertad condicional, que no tenían más razones para quedarse. Menos razones tendrían muy pronto los nativos para querer que se quedaran"

Gabriel García Márquez, comisionado. Colombia al Filo de la oportunidad. Documento de los sabios
La resistencia sobre los hechos históricos más dolorosos se queda muchas veces reclamando o sanando heridas de un pasado muy distante, distrayendo su atención de los problemas sociales actuales, que si bien, pueden tener como núcleo momentos irresolutos de la historia, exigen una posición más crítica y activa que permita mirar el presente con decisión de cambio y no solo como un eco del pasado que hace sangrar las heridas con cada una de sus réplicas.

En Colombia, después de la constitución de 1991, en la que se invirtieron todas las esperanzas en una gran apuesta por la transformación de los derechos civiles y los ámbitos de participación, se recuerda hoy día como 
una de las quimeras paradigmáticas de nuestro pasado, dado que abrió una brecha en diversos frentes, políticos, sociales, educativos y culturales. La consolidación de nuevas posturas frente a las narrativas de la historia y las versiones de nuestro pasado permitió una mirada crítica a los ciudadanos y reposicionó a los visitantes de los Museos, quienes pasaron de ser simples espectadores a participantes activos de las discusiones y de los contenidos que la institución Museo brinda.

Paulatinamente los ámbitos culturales se convierten en escenarios aptos y necesarios de participación, donde los contextos de la historia se confrontan y a partir de ellos se construyen procesos de intercambio de saberes, de conocimientos, de pensamientos, que propicien transformaciones reales en la comunidad.

La reconstrucción de la historia latinoamericana esta edificada en una acción de permanente resiliencia, en un construir en lo echado a perder, al borde de una desesperanza que corre el riesgo de adormecerse en el acostumbramiento. El escenario de lo cultural es ahora más que nunca el escenario de lo político, un lugar donde rebatir sobre las verdades de la historia, donde los sujetos reconocen su identidad, no como una marea de ideas en un solo sentido con el peligro del adoctrinamiento, más bien, sobre el desarrollo de ideas innovadoras desde el poder de lo colectivo y nutridas por su diversidad.

Esta transformación de los Museos demuestra cómo poco a poco los escenarios de lo público son apropiados por los ciudadanos, quienes encuentran en ellos nuevas maneras de comprender y poner en diálogo sus propios contextos. Las comunidades ahora adaptan el lenguaje de lo museológico como una alternativa para establecer una posición, para exponer sus ideas, logrando con ello un empoderamiento de sus realidades, entendiéndose dentro de las mismas como eje de transformación. El Museo se vislumbra entonces como alternativa para el diálogo, para confrontar los puntos de vista y gracias a los múltiples disensos entender sobre nuevos mecanismos para la resolución de conflictos, para la toma de decisiones y para la consecución de acuerdos. La estructura jerárquica del Museo se presenta a sí misma en entredicho y logra en muchos casos disminuir la brecha entre la labor netamente académica y su potencial como ente transformador social.

Es bien sabido que las dinámicas internas de los Museos son un reflejo de la realidad política del lugar donde se encuentran, siendo sus diálogos internos una negociación no siempre equilibrada de los poderes que lo sustentan. Por eso, los primeros campos de negociación se deben edificar al interior de los mismos museos, encontrar la justa medida para que los proyectos o programas sean cada vez más transversales y ostenten sus resultados como un aparato dinámico y compacto, de logarlo, esa estructura desarrollará en sus resultados un mayor impacto. No obstante dinamizar la rígida y tradicional estructura del Museo no es tarea fácil, depende de la flexibilidad con que se brindan alternativas de co-creación entre los diferentes especialistas y desde las diferentes disciplinas que allí se albergan.

\section{La noción de libertad}

Cuando un proyecto cultural se propone incursionar en estrategias transformadoras, muchas veces se cae en el error de enfocar los esfuerzos únicamente en los sujetos externos, en los visitantes, sin embargo, cuando la noción es clara al respecto de lo que implica semejante empresa, se empieza por comprometer a los trabajadores de museos en un proceso de transformación al interior de éste, lo cual compete a todas las instancias, en todos los niveles y en sus actividades cotidianas, que en principio ya parecían claras.

Es entonces cuando nos encontramos con todo tipo de estrategias para llegar a una transformación institucional, a una nueva estructura y se emprenden acciones de gestión humana y de transformación de procesos, que implican una revisión crítica y veraz que no oculte las debilidades ni los errores que surjan en el proceso, por el contrario, exige que se facilite un ambiente propicio para el diálogo que permita llegar a una comunicación libre y sin prejuicios.

Cuando pensamos el Museo como alternativa para la resolución de conflictos, en verdad trascendemos los proyectos y programas que se diseñan con y para los públicos y llegamos a entender que la disposición de un ambiente semejante es viable, si y solo si es parte estructural de la institucionalidad del Museo, es decir, si los conceptos que el museo propende en comunicar e implementar, se impregnan en la esencia misma de su estructura funcional. Esto se puede evidenciar, cuando el Museo se compromete a tal punto que define su norte en este sentido e involucra incluso en sus estatutos, en su definición, en su misión las palabras clave para redirigir el norte de su apuesta y por lo tanto la visión en su quehacer.

Logar la sintonía entre el discurso y la acción, exige la desambiguación de algunos conceptos y pone de manifiesto la necesidad de generar un diálogo en torno a ellos antes de abordar las inmensas coyunturas de lo cotidiano.

\section{Transformación de los conceptos}

La dinámica del museo espera cada vez más la participación de los visitantes, y para ello se permite y les permite ciertas libertades. Es en torno a esa noción de libertad que rondaremos algunos ejemplos que permitirán reflexionar y confrontar lo que acontece en los discursos y acciones manifiestas en los museos, en sus políticas y en sus trabajadores. 
A lo largo de Latinoamérica se construyen proyectos expositivos que convergen en el concepto de LIBERTAD, sobre la cual se edifican las ideas de nación y democracia. Pero más allá de definirla, justificarla o rebatirla en estos contextos de lo histórico, es también interesante poder debatir sobre la percepción de libertad en el presente, pensada como un estado que puede ser físico, mental, espiritual, etc., sobre cómo puede relacionarse con nosotros como individuos, de cómo podemos sentirla, buscarla, exigirla o merecerla. Lo inquietante es que parece estar distante o ausente, pues se manifiesta una permanente necesidad de encontrarla, sin ser conscientes del estado de libertad en el que podamos estar eventualmente.

Pensar en un sujeto crítico, en un visitante activo, exige pensar en un contexto que permite la expresión y por lo tanto respeta la libertad de expresarse, de estar en desacuerdo si es el caso. Sin embargo, los lenguajes confrontan a los sujetos sobre estas percepciones e incluso pueden jugar con su sensación de libertad. Un discurso bien armado, bien justificado y perfectamente mediado, puede llegar a convencer sobre algo que está totalmente en contravía de nuestras ideas y convicciones.

\section{Primera noción: la libertad de lo cotidiano}

Si pidieras los datos de tu operador de telefonía celular, como lo hizo Malte Splitz, del partido verde alemán, quien solicitó la información que emite su móvil durante solo seis meses, y con ella realizó gracias a un proceso de geo referenciación, un mapa dinámico que muestra detalladamente todas las actividades de Malte durante este tiempo, el resultado es un modelo que da cuenta de cada una de sus ubicaciones y actividades, con quien habla, que habla, los mensajes que escribió, los recorridos hechos y los medios o vías que utilizó, los lugares y negocios que frecuenta, etcétera, etcétera.

Así mismo, cada teléfono móvil y cada acceso o emisión de datos de nuestros aparatos electrónicos transmiten información detallada de nuestras actividades. Cuando hacemos uso de las aplicaciones o productos gratuitos, que para activarse nos solicitan permisos y acceso a la ubicación por GPS del dispositivo, a los fotografías y carpetas de contenido, a los medios de almacenamiento y al uso de nuestra información personal, estos datos son solicitados y autorizados a diario con la idea de hacer nuestra vida "más fácil", entonces sentimos ese poder manifiesto que parece darnos las tecnologías.

En diferentes momentos de la historia la tecnología ha representado una apertura al conocimiento, pero esa ventana se ha abierto a discreción de quien ostenta los roles de poder. Tener el acceso al conocimiento a través de las tecnologías da la sensación de tener ese poder en las manos, lo cual puede ser verdad hasta cierto punto, pues quien maneja el conocimiento lleva a su favor la ventaja.
Actualmente accedemos a una cantidad de información ilimitada, con tal volumen y variedad que no nos alcanzan las horas de la vida para poder navegar todo ese universo. Sin embargo, ¿es esa libertad ilimitada? ¿Es realmente una sensación de libertad a la que aludimos para, de alguna manera, ostentar ese poder?

En ese momento nos damos cuenta de que el acceso a la información y de hecho el acceso a nuestra información compartida por cláusulas de permisibilidad, trasgrede esa aparente libertad con la que accedemos a la información que en principio es pública. Especialmente los niños cuando manipulan una tecnología y autorizan cualquier aplicativo, quedan expuestos y exponen la seguridad de la información que creíamos privada.

Este ejemplo abre una pregunta que no siempre queremos hacer, ya que la absoluta necesidad de acceder a esa información y estar conectados en ese tránsito de comunicación del día a día, prima sobre las más básicas premisas de auto conservación. Aquello que en principio nos hacía libres, al verlo en perspectiva nos hace controlables, rastreables y hasta predecibles. La información que recogen de cada uno de nosotros es convertida en un producto más para la venta y son las grandes compañías las que hacen uso de esa información, nos venden la ilusión de solucionarnos una necesidad al hacernos llegar a nuestros dispositivos ofertas y opciones de acceso y descuentos, los cuales se activan con solo estar en un lugar, comparar una u otra marca, e incluso en una simple e inocente conversación.

Las dinámicas de socialización y las presiones que genera cada etapa de la vida nos involucran en el azaroso afán de pertenecer a la manada, de hacer parte de algo. Allí, las preguntas existencialistas más básicas parecen diluirse, construimos la realidad que queremos y le damos sentido a tal punto de creer.

Las sociedades dan cuenta de conceptos sobre los cuales edifican su realidad, y la manera en que ellas dan sentido a nuestra historia dependiendo de quién la escriba, sustenta los hechos a conveniencia. Por ello para hablar de ambientes liberadores como los museos, es importante evidenciar los canales que se establecen casi imperceptiblemente en ámbitos que van desde los medios de comunicación, hasta la educación misma.

\section{Segunda noción: la libertad una idea que se transforma a voluntad}

En ocasiones uno escucha mencionar a los jóvenes, querer "ser diferente como los demás", y sobre tal ambigüedad se establecen las nociones de libertad, nociones que hacen parte de las diferentes instancias de lo político y de lo social, que muchas veces determinan el pensamiento colectivo y "dan sentido" a lo identitario. 
Se habla de diversidad-igualdad, como elementos definitorios para el concepto de ciudadanía y aunque estos términos pueden ser contrarios, evocan una categoría que permite ubicarnos en un contexto de amplia complejidad, que por un lado reconoce nuestras singularidades, y por el otro reafirma los elementos sociales que nos definen como iguales desde el punto de vista de lo colectivo. Estos parámetros que la sociedad ha empleado para cimentar las transformaciones históricas han minimizado de una u otra forma las diferencias sociales.

Las palabras y su profundo poder, transforman progresivamente nuestra actitud frente a aquellas actitudes que discriminan y desconocen al otro como igual, a pesar de su naturaleza singular. Hoy se habla mucho de Inclusión-alteridad y muchas veces se adelantan iniciativas que buscan disminuir esas brechas que nos fracturan o nos dividen. Sin embargo, las acciones de responsabilidad social, que vemos a diario no siempre actúan responsablemente, en ocasiones solo disfrazan buenas intenciones con maravillosas campañas publicitarias y eventos para mostrar o demostrar sus acciones; por ello el control social es fundamental, por eso los ámbitos culturales son una muy buena herramienta para construir de manera conjunta alternativas y acciones que marquen la diferencia.

¿Es posible pensar el museo como un ambiente liberador, cuando sus discursos están basados en ideas y conceptos que dan sentido a una verdad histórica oficial?, pues bien, "el pasado es una historia que nos contamos a nosotros mismos", y la adaptamos a las necesidades con diversas modificaciones, pero básicamente nos recuerda que cada uno le da sentido a su realidad, de igual forma a su libertad.

El primer ejercicio de inclusión se hace allí, en la institucionalidad del Museo, debe permear esa relación entre las áreas, entender al otro, su trabajo, sus puntos de vista y construir sobre la diferencia. En últimas ese primer ejercicio de alteridad permite reconocer al otro, fortalecer el trabajo en equipo y los esfuerzos de cada una de las instancias del Museo, generando ambientes que propicien reinterpretaciones, diálogos y nuevas miradas, que permitan confrontar la historia y refrescar la realidad.

El museo no logrará ser un espacio para la resolución de conflictos o para el diálogo a menos que propicie y permita el diálogo entre sus profesionales y trabajadores en todas las áreas. Es entonces necesario convertirlo en un espacio de construcción, de acuerdos y por supuesto de desacuerdos, un ambiente sin desacuerdos sería muy aburrido, pero si del disenso no se llega a un consenso, puede ser inocuo.

\section{Castigo vs Reparación:}

Las heridas del pasado, sobre todo las heridas históricas suelen dejar varias brechas abiertas, si bien, algunos hechos están inmersos en el profundo pasado, el verdadero aprendizaje es la no repetición, la reparación como un ejercicio de reconstrucción, de resiliencia. Los procesos de nuestros países hermanos son en mucho diferentes, por tal razón la instancia de perdón y olvido no pareciera ser una alternativa fácil de incorporar. Se requiere de un cambio generacional, establecer una nueva lectura de nuestro pasado y recuperar en el presente los vacíos del ayer, resignificando y construyendo nuevos escenarios, y para ello el Museo es una alternativa poderosa.

Hay que establecer diálogos con sensatez, hay necesidad de ablandar los canales que se han endurecido con el tiempo, renovar los medios que han estructurado las versiones de la historia y construir sub-versiones de esas memorias del pasado que nos permitan repensar nuestro presente.

\section{La noción de realidad en la noción de libertad.}

"El arte es una mentira que nos permite decir la verdad"

Picasso

"La historia, indicaba Michel Foucault, transforma el monumento en documento; pero no siempre es cierto: a menudo monumento y documento se sitúan en una vía de doble dirección". El beso de Judas.

Joan Fontcuberta

Verdades, ficciones y dudas razonables...

Tal vez un buen ejemplo de ello subyace en la obra del artista Joan Fontcuberta, en especial sus series donde el FAKE cumple un valor fundamental construyendo desde las fuentes que sustentan las realidades históricas, una realidad alterna que se vuelve tan creíble que se instala en la memoria y se aferra en aquellas certezas de nuestro entorno. Sin embargo, él, Fontcuberta, plantea sus ocurrencias, sus ironías, y se delata a sí mismo para lograr una tensión que permita al espectador un momento de incertidumbre que incite a la duda y pueda determinar su falsedad. Aun así, muchos pasan desapercibidos el FAKE, y continúan creyendo las versiones y en muchos casos legitiman lo que ven, por el lugar donde lo ven, es decir, la institución, el museo, la biblioteca, la pinacoteca, en fin, el estandarte institucional ratifica la verdad y las personas confían en ese estandarte. Lo mismo sucede con los medios de comunicación, con los titulares de prensa, con las telenovelas, libros de texto educativos, revistas de variedades, la internet, etc.

La misión real y responsable del mediador yace en 
controvertir en estos ámbitos de lo institucional las reflexiones de los hechos del presente, no importa el tipo de institución o museo que sea, son un escenario de lo público, de lo político y deben ser lugares de participación por excelencia.

Algunos hablan de la neutralidad de los museos a la hora de abordar los temas incómodos de la realidad nacional o local, de las posturas religiosas o políticas, de la ética, la moral o de las convicciones. Pero entonces ¿cuál es la verdadera labor del Museo? y si el objetivo es proyectarse como un ambiente de transformación social, ¿una actitud de total neutralidad no se vuelve en si contradictoria?

Los Museos son repositorios de lo humano, no todos son de arte, pero los objetos que allí se albergan son expresiones del ser humano y en ese sentido son como obras de arte, pues adquieren un sentido gracias a una interpretación que es codificada con un sentido y decodificada una y otra vez, por lo tanto, sus significados cambian todo el tiempo. Ese objeto, ese elemento de la memoria sea tangible o intangible, tiene muchas aristas, tiene muchas formas de construirse y esas direcciones que toma su significado están en nuestras manos.

Ahora los FAKE news están a la orden del día y han adquirido un lenguaje de justificación inadecuada, incluso en algún punto la mezcla entre la realidad y la ficción alimenta la incertidumbre que, aunque parecen una mentira, lamentablemente terminan siendo verdades.

El trabajo que hace Fontcuberta al usar el FAKE como un ejercicio critico que pone al espectador frente al reto permanente de cuestionarse a sí mismo es supremamente ambicioso. De su serie Sputnik, por nombrar solo un ejemplo, el artista toma un momento histórico fácilmente reconocible y recordado, la carrera espacial entre E.E.U.U y la Antigua Unión Soviética de la guerra fría, en la cual se narra la historia de un cosmonauta ruso que viaja en la Soyuz II a una misión espacial y todos los documentos que expone ratifican la existencia de este personaje, con fotografías, objetos, instrumentos y una convincente narración, da nacimiento a un héroe nacional ruso llamado Iván Istochnikov.

Lamentablemente durante la misión, un meteorito impacta contra la nave y el cosmonauta sale despedido al espacio, generando el pánico en tierra, donde no saben qué hacer, pues Rusia no podía admitir el fracaso, sería inconcebible. Con su último aliento el cosmonauta escribe una nota, la pone dentro de una botella de Vodka y la lanza al espacio, con la ilusión que llegue a la tierra y alguien la encuentre para ir en su rescate. La exposición muestra la foto de su perrita Kokla, quien lo acompaña en esta tragedia, los documentos y muestras científicas son construidos en parte con documentos o imágenes reales que son fácilmente reconocidas y refuerzan la sensación de verdad.
Es muy interesante el comportamiento de los públicos frente a las restricciones anunciadas en la sección de aislamiento donde reposaba el meteorito que chocó la nave, un anuncio indica que el ingreso de mujeres embarazadas, personas con marcapasos y niñas con trenzas está prohibido, a lo cual muchas personas, no solo niñas, desataban sus trenzas para poder observar tan exótico objeto espacial.

Esta serie causó tanto impacto que incluso se habla de la historia del cosmonauta perdido, en programas de temas paranormales y existe un disco completo de un grupo musical ruso dedicado al cosmonauta Iván Istochnikov.

Las fotografías que usa Fontcuberta pueden ser modificaciones de imágenes originales o construcciones de imágenes completamente irreales, pero lo suficientemente bien logradas como para hacernos creer que son reales. Incluso los documentos están tan bien logrados que pasan por originales, sumado a ello el estar en una vitrina, en una exposición y en uno u otro museo lo hace completamente convincente. Esto abre otra dimensión cuestionable de las libertades en el uso de las imágenes, no solo sobre el acceso ilimitado a ellas, también sobre su uso adecuado o sobre el complejo campo de los derechos de autor, derechos de uso, entre otras.

Actualmente la legitimidad u originalidad se comprueba o se legaliza por medio de un documento, antiguamente la confianza permitía cerrar un trato con solo estrechar las manos, se hacía un trueque o intercambio de un objeto por otro sobre la base de la confianza. Las relaciones que establecemos socialmente, en principio basan su legitimidad en el mismo principio, la confianza, esperamos que toda aquella información que nos llega por uno u otro medio sea veraz, y muchas veces confiamos ciegamente en ella. Sin embargo, la historia misma nos ha comprobado que nada es irrefutable.

Durante la exposición titulada Pareidolia, en el Museo de Arte Miguel Urrutia en Bogotá, la obra de Fontcuberta dio la posibilidad al área educativa, de preguntarse abiertamente sobre qué hacer con los públicos y esas historias tan particulares como las que él nos presenta, de tal manera que se lograra mediar con los diversos públicos una narrativa entre la verdad y la ficción. La exposición se llevó a cabo sobre los meses de noviembre y diciembre, lo que permitió utilizar algunos elementos de la cotidianidad, en las actividades más populares y concurridas de estas épocas. Con la participación de un astrónomo certificado, se instaló una cúpula en la cual se proyectaban historias fantásticas, pero irreales que reforzaban el triste final del cosmonauta ruso, o una historia sobre el origen de la estrella de Belén, con argumentos fantásticos de ovnis y alienígenas que confrontaban a padres e hijos entre preguntas que no sabían muy buen como ser respondidas. Luego en sala se encontraban con la visita a la exposición, que era conducida por un Grinch, que entre historia 
e historia trataba de subrayar aquellos elementos que pudieran despertar la sospecha del engaño, pese a ello, muchos luchaban por rehusarse a aceptar que estaban en un error o que habían sido engañados.

Como mediadores de museos tenemos ese poder de la palabra en nuestras manos, poder que representa una gran responsabilidad, pues si logramos conectar a los visitantes con nuestros relatos, podríamos llevarlos a cualquier lugar. Existe una profunda incertidumbre en dejar ese barco a la deriva, pues estimulamos todo tipo de experiencias y no tenemos responsabilidad de lo que venga después, solo esperar que tenga un buen destino, sin embargo, es importante aludir a la confianza y dar todos los elementos para que ese sujeto tome sus propias decisiones y construya su propia carta de navegación.

\section{Prohibido prohibir}

Es necesario cambiar los lenguajes que tradicionalmente han generado una distancia entre la experiencia de los visitantes y los límites de lo permitido, sin entrar en conflicto con la misionalidad que los museos tienen frente a la salvaguardia de los patrimonios que alberga. En una consulta hecha a los niños sobre su expectativa frente a la visita a un museo, se les preguntó, ¿Qué es lo que te gustaría hacer cuando vas a un museo?, un niño respondió, "Uno va a un museo a portase bien", y sobre este prejuicio se han programado interminablemente las visitas escolares y aquello que debería ser una reflexión sobre el cuidado de esos patrimonios, termina siendo un postulado poco amable y que para nada invita a pensar en una experiencia acogedora.

Esto ha llevado a incorporar un lenguaje desde la negación, que más allá de establecer unos límites o unas reglas de comportamiento, impide que los públicos enriquezcan sus perspectivas e incorporen un léxico incluyente y constructivo. Si la pretensión es generar ambientes de apropiación, experiencias que permitan encontrar puntos de reconocimiento con los cuales identificarse, es claro que el trabajo educativo tiene la batuta a la hora de facilitar conversaciones y ambientes propicios que hagan sentir bienvenidos y empoderados a los visitantes.

En una visita al complejo arqueológico de Tiahuanaco, se encuentra uno con un aviso que contiene once recomendaciones para los visitantes, las cuales están antecedidas por la frase "Está prohibido..." y que delimitan muy bien las acciones que podrían generar algún daño en las estructuras y piezas que allí se conservan, pero que predispone a los visitantes antes de iniciar el recorrido. El impacto de un proyecto educativo que transforme esta misma información en reflexiones que permitan entender las preocupaciones por la conservación de este patrimonio y empodere a los públicos de esa intención de proteger y dar sentido de pertenencia, plantea un cambio en el pensamiento del colectivo que sería tan significativo como la experiencia misma de estar allí.

\section{Pequeñas historias que se vuelven grandes realidades}

Así como los viajeros del siglo XIX, que con sus breves historias describieron las características de un lugar $u$ otro, con micro relatos tan convincentes que se vuelven postulados, pero que a la larga determinan la percepción de un todo desde un solo punto de vista. Estas versiones al crecer en el imaginario de lo colectivo convierten la mirada de un solo sujeto o de un pequeño número de ellos, en una verdad absoluta que al ser creíble se destaca entre los demás como un gran relato de los hechos. Entonces la historia que contamos, por más verdadera o ficticia que sea, corre ese mismo proceso y puede convertirse en un gran macro relato, de lo establecido, con sus reglas y determinaciones.

El museo es un detonador de posibilidades, un generador de nuevas miradas, el lugar de la confrontación del conocimiento, donde la sensación de libertad debe propiciarse en la experiencia, quitando el miedo sobre el saber o no, e incentivando la curiosidad, donde el asombro no sea el fin sino el inicio de la experiencia y procurando que la necesidad del conocimiento y el deseo de saber no se sacien solo en el cierre de un acto casi espectacularizante, incluso debe contemplar el rechazo tanto como el goce, de lo que se ha llamado la experiencia significativa.

\section{El museo como generador de posibilidades.}

Pasar de un lenguaje restrictivo a uno sugestivo, propiciar experiencias y situaciones que construyan nuevas prácticas, convierte al museo en un ambiente propicio para experimentar otras alternativas de visita, otras posibilidades de construcción colectiva y de intercambio de saberes, donde las conclusiones se den en la marcha y no como un objetivo prefabricado y determinativo de la institución.

Esto es posible al construir con la comunidad, dialogar, escuchar y registrar las experiencias para construir sobre ellas otras nuevas. Consiste en trabajar con el otro y de intercambiar miradas y conocimientos que solo se transmiten en un ambiente de confianza, es decir, hay que construir sobre la confianza, la cual se gana no se conquista, es un intercambio consentido y dual o grupal. Ese trabajo de acercamiento se da dentro y fuera del museo, por lo que los educadores deben salir de la zona segura de sus instituciones y ampliar sus zonas de confort.

A veces corremos el riesgo de quedarnos atrapados en los relatos, en las versiones creíbles y comprobables; pero al romper la barrera de nuestra zona segura, confrontamos como sociedad las versiones del pasado con los contextos 
actuales y las problemáticas latentes.

Aunque es posible que encontremos pares o similares en uno $u$ otro lugar del mundo que permitan trabajar sobre temas comunes, no podemos implementar un modelo educativo foráneo o una acción participativa con un manual de instrucciones a bordo, es claro que no existe una fórmula que responda a todos los museos en su diversidad, o que encaje en todos los contextos y realidades. Lo que si podemos lograr es construir en colectivo, incluso entre pares educadores o desde programas y proyectos afines. Una gran red es la mejor respuesta, registrar nuestras experiencias y compartirlas en todo tipo de escenarios con la convicción del intercambio de saberes, del fortalecimiento de la labor del Museo como un agente de transformación social.

Museo y comunidad funcionan y se adaptan tal y como lo harían dos organismos o sistemas vivos en donde existe una relación simbiótica. Se habla en ocasiones en un ambiente rizomático que desarrolla todo tipo de conexiones y variables que son independientes a la instancia central, de hecho, pueden transformar los objetivos de dicha instancia. Tal es así, tanto en los modelos de museos tradicionales que permiten esta dinámica, como en los modelos de museos comunitarios o las comunidades que hacen de la actividad museológica una herramienta dentro de los procesos de sus comunidades.

Muy apropiadamente el museo desde sus áreas educativas ha incorporado las prácticas de la comunidad como herramienta pedagógica y de una manera muy afortunada se incorporaron acciones de inclusión que hacen parte de la cotidianidad, no como actividades aisladas, especiales o políticamente correctas, sino totalmente abiertas y pertinentes, ajustadas a los ritmos de la comunidad.

La agitación de la vida diaria y los afanes de lo urgente que nos hace olvidar lo realmente vital y necesario, impide construir desde lo más simple. Hoy día vivimos en estructuras modulares de interminables edificios que han transformado la idea de barrio, la idea del vecino, nos alejamos paulatinamente de acciones tan sencillas, comunes y cotidianas que hacen parte de la vida diaria, del construir en comunión, del compartir.

Las actividades de lo cotidiano que al repetirse se hacen tradición, corren el riesgo de perder su valor, ahora hay espacios que lo suplen y mercantilizan las necesidades básicas. Al generar espacios para lo comunitario, el museo no solo rescata las prácticas de la comunidad, sino que además construye con la comunidad y para la comunidad nuevos escenarios de apropiación.

\section{Algunas experiencias para compartir:}

En los años 90 el Museo Nacional de Colombia realizó una gran encuesta en la que se preguntaba a los ciudadanos ¿Qué quisiera ver expuesto en el museo?, y las personas respondieron cosas que en principio sonaban absurdas o inapropiadas para algunos, sobre todo para los más ortodoxos. Decían, queremos ver los reinados de la belleza, las telenovelas, el rock, entre otras y unos años después la curaduría apostó por responder a esas sugerencias y como resultado se produjo una exposición llamada Nación Rock 2007-2008, en la cual se reconstruían algunos momentos de la historia a través del rock y de cómo este influyó en algunos grupos sociales y políticos incluso, abrió la posibilidad para que algunos grupos musicales tocaran en el auditorio del museo desacralizando este importantísimo escenario.

Así mismo vinieron las exposiciones Acción Cine en Colombia 2007-2008. Si lo tiene Tráigalo 20082009, una exposición que invitaba a los públicos del Museo para contribuir a complementar las colecciones. Velorios y santos vivos. Comunidades negras, afrocolombianas, raizales 2008-2008 donde las comunidades afrocolombianas compartieron sus tradiciones y prácticas funerarias. Llegó el Amazonas a Bogotá 2009-2009, expuso las diversas problemáticas de las hermosas selvas colombianas y los lamentables sucesos de esclavitud y explotación de las comunidades indígenas en pleno siglo XX. Un país de telenovela 2009-2010, una selección de 10 telenovelas que daban cuenta de los procesos históricos de diferentes regiones de Colombia. Un país hecho de fútbol 2011-2012, que además de narrar desde las miradas de hinchas, jugadores las memorias de este deporte, daba un contexto muy importante de las circunstancias históricas vinculadas con el futbol, fueran o no afortunadas.

\section{Sabores con historia y la comida prehispánica}

Taller Comida Prehispánica por María Buenaventura. Museo Nacional de Colombia - 2010. Una maravillosa actividad liderada por la artista María Buenaventura, quien construyó a través de las recetas prehispánicas y coloniales un recorrido por la historia con sabores y aromas. Toda clase de públicos asistió y aportó su versión de la historia al compartir sus propias recetas.

\section{Cuerpo y memoria (corporalidad)}

Taller corporalidad por Lina Ricaurte. Museo Nacional de Colombia - 2008. Aludiendo a una de las prácticas más antiguas de la humanidad, la pintura corporal, esta actividad invita a intervenir el propio cuerpo como un tatuaje temporal en el que se expresan elementos de la identidad de cada persona, los cuales se asocian a significados personales y colectivos.

Encuentros entre generaciones (primera infancia y adulto mayor) 
Programa Explorando patrimonios, (niños y niñas en situación de vulnerabilidad y programa Adulto mayor). Museo Nacional de Colombia - 2010. Dos proyectos permitieron el encuentro de los abuelos que hacen parte del programa para adultos mayores y el programa Explorando Patrimonios que trabaja con niños en situación de vulnerabilidad, en este caso, niños que esperan un proceso de adopción o que han sido retirados de sus núcleos familiares por diferentes situaciones de maltrato o violencia intrafamiliar.

\section{Programa de accesibilidad}

El programa de accesibilidad del Museo Nacional, dirigido a aquellas poblaciones que por una u otra razón no acceden a los museos. Inicialmente se concentró en la población con discapacidad y rápidamente incorporó acciones y actividades hacia otras poblaciones facilitando su acceso y experiencia con aquellos patrimonios que parecían lejanos. Un buen ejemplo es el trabajo de visita que se desarrolló con los presos de la cárcel distrital, quienes se encontraban en proceso de formación y reincorporación a la vida laboral.

Esta visita permitió construir nuevos guiones y nos exigió adentrarnos más profundamente en los textos históricos que dan cuenta de la antigua cárcel hoy Museo Nacional de Colombia. El Libro Secretos del Panóptico de Adolfo León Gómez, narra todo tipo de historias relacionadas con el día a día de esta cárcel y muchos de sus relatos no solo develan los comportamientos y anécdotas dentro de sus muros, sino que además ponen en contexto la realidad de la ciudad de Bogotá a finales del XIX e inicios del XX.

La experiencia es bastante compleja, si pensamos que, a los presos de la actual cárcel distrital como premio a su proceso de socialización, los favorecían con una visita al Museo Nacional que era otra cárcel, la visita despertaba todo tipo de tensiones, preguntas y suspicacias. Sin embargo, estas tensiones fueron herramienta eficaz para neutralizar la complejidad de las preguntas que iban desde inquietudes formales o espaciales, hasta, posibles fugas o muertes dentro del antiguo penal.

La seguridad para poder llevar a cabo estas visitas era muy compleja, se acordó con el INPEC que el modelo de visita exigía medidas de seguridad avanzadas, como programar la visita un lunes previamente acordado, aprovechando que en este día el museo está cerrado al público, se desplegaba todo un operativo de seguridad para la llegada, los presos venían acompañados por guardas armados y sus manos esposadas. Todo ello generaba una incómoda tensión, por lo que se trabajó con los mediadores y se planearon las actividades de tal manera que se lograra un desarrollo tranquilo y una conversación abierta y des complicada con los presos visitantes.

Las visitas fueron muy exitosas, pues se convirtieron en un intercambio de historias, de anécdotas, de preguntas a veces un poco morbosas, pero finalmente preguntas que venían de un contexto carcelario real y que a los mediadores educadores del Museo les abrió un enorme campo de posibilidades para enriquecer los contextos de las próximas visitas, e incluso algunos de los elementos de aquellas experiencias se incorporaron en las visitas generales que se daban a los demás públicos. De allí surgió un piloto de recorrido temático que se hacía en grupos, a modo de carrera de observación pero que exigió que cada grupo tomara un rol, por un lado, el de los presos y por otro el de los guardas, y desde esa perspectiva encontraban los vestigios de la antigua cárcel entre los montajes y objetos de la colección.

Las actividades que se dan en ámbitos enriquecidos de posibilidades y que permiten ajustar el rumbo durante el camino, logran renovar la experiencia en el museo y se refuerzan dejando inquietudes que el visitante se lleva consigo. Algunos de los mejores resultados cuando se diseñan actividades y programas tan poco convencionales, es que pueden tomar rumbos insospechados que quiebran la visita modelo, la cual generalmente tiene un único objetivo.

Cuando el visitante propone y dispone surgiendo, descubriendo e incorporando nuevas posibilidades, encuentra una zona segura en la cual compartir sus conocimientos y saberes sin prejuicio alguno y muchas de estas experiencias son finalmente incorporadas al museo en el contexto de la práctica de mediación, asimilando conceptos y saberes que se vuelven indispensables como herramientas reveladoras que permiten dar los giros que sean necesarios para lograr una experiencia significativa a cualquier nivel.

La propuesta es que se incorporen conceptos que permitan a los educadores y sobre todo a los públicos, impregnarse de estas posibilidades y por lo tanto tener las libertades de desarrollarse en el medio que el museo les ofrece para ello, propiciar los escenarios para la deconstrucción de significados y la construcción de identidades, sobre todo de sus propias identidades, encontrando los vínculos que les permita distinguir los patrimonios donde se vean representados.

El cuerpo como repositorio de la memoria es moldeable y libre de llevarse las ideas que les sean de utilidad y así construir la idea de ciudadanía en el reconocimiento de sus particularidades. Reescribir la historia en colectivo en un ejercicio de incorporación a su propia historia, reconociendo y reconociéndose dentro de ese contexto, recordar, crecer y crear en el proceso, con ideas que se mezclan con las actividades de la vida diaria. Reconstruir y reactivar por medio de la experiencia y la imaginación, hallar el lado poético al permitirse re imaginar, reutilizar y trascender, poner en ejercicio los mínimos vitales de la convivencia, con acciones tan sencillas como escuchar, 
observar y dialogar e incluso errar, como una posibilidad de aprendizaje.

Hay que generar nuevos grupos de aprendizaje y potenciar la formación de los formadores, de los mediadores y de todos los equipos que trabajan en el Museo. Grupos de estudio, de voluntariado, con los vigilantes, proyectos transversales entre áreas y acciones que impacten dentro y fuera del museo.

Construir alternativas de aproximación entre pares, con experiencias periféricas externas, con aquellos públicos que no suelen frecuentar el museo y darse el tiempo para visitarlos también. Involucrar a los protagonistas de los temas fuertes, como actores del conflicto, en ambientes de reconciliación o por lo menos del diálogo. Permitir que el escenario del museo sea compartido con experiencias comunitarias.

En el Museo Nacional se trabajó con las Mujeres Tejedoras de Mampuján, una fuerza femenina que apostó por el perdón en un trabajo comunitario que transforma. Un grupo de lideresas que ayudó a las comunidades de los Montes de María a superar los dolores y traumas de la guerra que se llevó a sus familiares y que los despojó de sus tierras. A través de representaciones simbólicas de sus vivencias en figuras de tela, lograron reconstruir sus comunidades en un impresionante ejercicio de resiliencia. Esta iniciativa nació en el campo, en el terreno de la vida cotidiana, pero que conquistó el escenario del museo y fue reconocido como un proceso de paz con acciones de memoria.

Cerrar con estos ejemplos, permite entender que cuando uno habla de resolución de conflictos, no solamente está remitiéndose al conflicto armado, o de la guerra de poderes, etc., también se está hablando de los conflictos de la vida diaria, de problemáticas a todo nivel que requieren de espacios donde ser abordadas, conversadas o resueltas en dado caso. Situaciones tan sencillas como adaptar el espacio del museo para los niños y permitirles tener una experiencia adecuada en un lugar que históricamente no ha sido diseñada para ellos, pasa de ser un ejercicio de inclusión a ser una acción liberadora de prejuicios para el mismo museo.

Las acciones liberadoras que permiten resolver conflictos son generalmente acciones que confrontan a los sujetos sacándolos de sus zonas de confort y permitiendo una sana confrontación al propiciar un espacio de diálogo constructivo en torno a este.
"La libertad, que es una conquista y no una donación, exige una búsqueda permanente. Búsqueda que solo existe en el acto responsable de quien la lleva a cabo. Nadie tiene libertad para ser libre, sino que al no ser libre lucha por conseguir su libertad"

Paulo Freire. Pedagogía del oprimido

Bogotá, Colombia 20 de abril 2019

\section{Agradecimientos}

Museo Nacional de Colombia y sus áreas de educación, Museos del Banco de la República y sus áreas de educación. Asociación de Trabajadores de Museo de Argentina. ICOM-MINOM.

\section{Bibliografía}

Carrizo, S. (2008) Escrituras del viaje: construcción y recepción de "fragmentos de mundo". Buenos Aires, Editorial Biblos.

Deleuze, G. Guattari, F. (1972, 1980) Rizoma, Introducción. En su proyecto Capitalismo y Esquizofrenia. Valencia: Pretextos, 2005.

Ellison, M., Jonze, S., Landay, V (productores) \& Jonze, S., (director) (2013) Her (Cinta Cinematográfica). E.E.U.U. Warner Bros. Pictures.

Fontcuberta, J. (1997, 2011, 2015) El beso de Judas, fotografía y verdad, Editorial Gustavo Gili, SL, Barcelona.

Future Journalism Project Media Lab (26 de noviembre de 2011) Tracking Malte Spitz. Obtenido de https://www. youtube.com/watch?v=J1EKvWot-3c

Freire, P (1970) Pedagogía del Oprimido. México, España, Argentina, Colombia. Siglo Veintiuno Editores.

Gómez, L, (1905) Secretos del panóptico. Bogotá República de Colombia

Valdés, E, A. Chaparro, L, F. Márquez, G, G. Gutiérrez, R. Llinás, Palacios, M. Patarroyo, M, E. Posada, E. Restrepo, A. Vasco C, E. (1994) Colombia: al filo de la oportunidadDocumento de los sabios - Misión de ciencia, educación y desarrollo. República de Colombia. Case, controles de administración y sistematización educativa. Editorial Linotípia Bolívar. 